\title{
BASES DE UN MODELO CONCEPTUAL PARA DECIDIR HECHOS*
}

\author{
Rodrigo Coloma Correa $* *$ \\ Universidad Alberto Hurtado \\ rcolomacorrea@gmail.com
}

RESUMEN. El presente texto se ocupa de algunos problemas que afectan la gestión de las pruebas y de los argumentos probatorios en sede judicial. Al respecto se proponen las bases de un modelo conceptual, en cuanto recurso que estandariza las posibilidades de ejecución de las tareas propias de un campo de trabajo. En el mundo de los jueces y de los abogados, los modelos conceptuales simplifican los problemas por la vía de declarar irrelevantes asuntos de detalle y, coetáneamente, de organizar eficientemente los distintos componentes implicados en la toma de decisiones. El concepto básico desde el cual se sugiere construir un modelo para gestionar los problemas probatorios es el de «hecho (probado)», entendido como un artefacto lingüístico que adscribe conductas jurídicamente relevantes y que supera un proceso de validación institucional.

Palabras claves: conceptos probatorios, hechos probados, modelo conceptual, pruebas.

\section{Basis for a Conceptual Model for Decisions on Facts}

ABSTRACT. The paper addresses some of the issues concerning the use of evidence and their arguments in courts. It offers the basis for a conceptual model as a tool that standardizes the possibilities of executing tasks within a certain field of activity. In the world of judges and lawyers, conceptual models simplify issues by declaring irrelevant matters of details and, at the same time, efficiently organizing the elements involved in decision making. The basic concept upon which the model for managing problems related to evidence should be built is «fact proven", understood as a linguistic artifact that ascribes behaviors legally relevant and overcomes a process of institutional validation.

Keywords: evidential concepts, facts proven, conceptual model, evidence.

\footnotetext{
* Fecha de recepción: 5 de julio de 2016. Fecha de aceptación: 28 de febrero de 2017.

Este trabajo es uno de los resultados de proyecto financiado por el Fondo Nacional de Desarrollo Científico y Tecnológico, FONDECYT 1140986 «Conceptos fundamentales del Derecho Probatorio en Chile».

** Facultad de Derecho de la Universidad Alberto Hurtado (Chile).
} 
—¿Qué tal Bill? —saludó el hombrecillo—. Te presento a George Mallory, el tío que ha subido a lo alto del Everest.

—Bueno, no del todo —objetó George-. De hecho...

-No te preocupes por los hechos, George — dijo Keedick, volviéndose hacia Mallory-. Aquí en Nueva York, nadie lo hace.

Jeffrey ARCHER, La senda de la gloria

\section{INTRODUCCIÓN ${ }^{1}$}

L

os argumentos que vierten tanto jueces como abogados difieren en su estructura y profundidad, según sea la problemática a la que refieran. Una muestra palmaria de aquello se observa en la manera de presentar argumentos que sirven de soporte a hechos o bien a interpretaciones de textos normativos. Cuando se enfrentan a asuntos de prueba, abogados y jueces, rara vez, desarrollan argumentos ${ }^{2}$ de una sofisticación equiparable de los que son capaces de producir si de lo que se trata es de dar cuenta de problemas de identificación o de atribución de significados a disposiciones normativas ${ }^{3}$. El asunto llama a la perplejidad, sobre todo porque en los últimos siglos, en aquellas disciplinas comprometidas, primordialmente, con la búsqueda de «lo verdadero» se ha logrado un desarrollo mucho más espectacular que en las que aspiran a identificar «lo bueno» ${ }^{4}$. ¿Qué ha pasado? Sin hacerme cargo de la pregunta en toda su magnitud, cabe intuir que una de las variables responsable de la precariedad en la gestión de los asuntos probatorios es la inexistencia de modelos conceptuales 5 .

Me propongo, en lo que sigue, esbozar las bases de un modelo conceptual para gestionar problemas de prueba o, más precisamente, para decidir hechos. Por cierto, lo que presento se aprovecha de discusiones académicas contemporáneas sobre esa clase de asuntos (las que aclaran bastantes cosas); y a la vez, toma en cuenta prácticas exitosas de abogados y jueces tendientes a la optimización de recursos probatorios, tanto si

1 Una versión preliminar se presentó en el seminario de investigación de Filosofía del Derecho de la Universidad de Alicante, en un curso de Argumentación de la Facultad de Derecho de la Universidad CastillaLa Mancha (Albacete) y en el seminario de la Facultad de Derecho de la Universidad Austral de Chile. Valoro todas las observaciones que allí me fueron hechas. Agradezco, especialmente, la minuciosa lectura realizada por Juan Carlos BAYÓN y Flavia CARBONELL, como también el eterno inconformismo de Claudio AGÜERO que me llevó a revisar varias veces algunos problemas que ingenuamente consideraba que estaban resueltos.

2 Con ello refiero a la mayor o menor fortaleza de las conexiones entre lo que no se encuentra problematizado (la base) y la conclusión a la que se llega. Una estructura argumental sólida reduce los saltos carentes de justificación y, en ese sentido, cuenta con credenciales para ser tomada en cuenta por los especialistas, más allá de los ocasionales desacuerdos. En el caso de los problemas de prueba, los argumentos, ya sea de abogados o de jueces, suelen ser difíciles de reducir a una forma estándar. En el caso de los problemas de identificación e interpretación normativas, si bien son frecuentes los desacuerdos (de fondo), hay una manera relativamente estandarizada de hacerse cargo de los problemas y de formular soluciones.

3 No se trata, por cierto, que los últimos sean sencillos (no lo son). De lo que se trata es que para jueces y abogados resulta mucho más familiar desenvolverse en territorios que los fuerzan a proponer, fortalecer, refutar o validar argumentos normativos, antes que en los que requieren definir conjeturas factuales, presentar pruebas y valorarlas.

${ }^{4}$ La analogía debiera resultar evidente: los problemas probatorios se aproximan a formas de operar en disciplinas comprometidas con la búsqueda de «lo verdadero», y los problemas normativos se conectan, de manera relativamente estrecha, con escenarios de búsqueda de «lo bueno».

5 Una explicación que asume cuestiones de cultura jurídica puede verse en COLOMA, 2016b: 273-275. 
de lo que se trata es de influir como de adoptar decisiones respecto de los hechos que se discuten en un juicio. Una de las claves para enfrentar satisfactoriamente el desafío anunciado radica en la acertada identificación de un concepto central en torno al cual construir el modelo. La presente propuesta asume que el modelo debe formularse en torno al concepto de «hechos». Los demás conceptos elegidos tienen una estrecha relación con el concepto de «hechos», y se ordenan según las etapas probatorias en las que adquieren especial protagonismo.

\section{MODELOS CONCEPTUALES PARA EL «MUNDO DEL DERECHO»}

\subsection{Entre el arte y la técnica}

En algunas disciplinas la estrecha comunicación entre ciencia y tecnología ha favorecido avances extraordinarios ${ }^{6}$. Aquella relación promueve que el progreso no dependa de la lenta dinámica del ensayo y error (¡la ciencia es útil!), como también facilita el constante escrutinio de las teorías científicas en la vida cotidiana ( $¡$ la ciencia se somete a contrastación!) 7 . Dicho en otras palabras, el tránsito desde la artesanía (que se desentiende de la ciencia) hacia la tecnología (que usa la ciencia), supone que cada nuevo desafío al que se haga frente no dependa de cálculos a «ojo de buen cubero», sino de la aplicación de fórmulas derivadas de teorías que, en caso de estar bien hechas, no tendrían por qué fracasar ${ }^{8}$.

En el campo ${ }^{9}$ de las ciencias jurídicas la aplicación tecnológica de los saberes disciplinarios pareciera encontrarse fuera de lugar ${ }^{10}$. De hecho, la competencia considerada como la más representativa de los jueces y abogados ${ }^{11}$ - y a la que con orgullo aludimos como razonar jurídicamente ${ }^{12}$ - no parece, en principio, susceptible de fortalecerse por vías que difieran de la observación rigurosa, de la práctica constante de tareas propias del campo jurídico y/o de la asimilación y adaptación de los consejos de los

\footnotetext{
${ }^{6}$ El alto prestigio que se reconoce a disciplinas como la física, la biología o la química depende —en gran medida - de la exitosa transferencia hacia procesos tecnológicos de lo que en ellas se encuentra validado a nivel teórico. Por cierto, no toda disciplina aspira al uso de sus teorías en la solución de problemas prácticos, como ocurre con la filosofía.

7 Esto incide en que si los productos no funcionan se revisará la tecnología utilizada y, en caso que los fallos perseverasen, se revisará la validez de los enunciados científicos que le sirven de soporte.

8 Hay, por cierto, un costo aparejado en la solución de los problemas mediante aplicaciones tecnológicas, esto es, la renuncia de asuntos de detalle. KOYRÉ, 1994: 117-145.

9 El campo de los juristas es un espacio de la interacción social en el que se les reconoce una posición preferente/exclusiva para la delimitación, gestión y solución de problemas jurídicamente relevantes, tanto desde una perspectiva teórica como práctica. El campo (de trabajo) de los juristas se ha dividido tradicionalmente en lo que se conocen como ramas del derecho. ColOMA, 2016b: 255-261.

${ }_{10}$ La tecnología resulta ocasionalmente visible en la fase de generación de información útil para el proceso probatorio (algunas pruebas periciales) y en la organización de la prueba disponible. Respecto de esto último cabe destacar desarrollos producidos a partir del chart method, propuesto originariamente por John Henry WigMORE.

11 El panorama posiblemente cambiará en el futuro. Así, por ejemplo, los avances en el rastreo de datos son cada vez mayores, aun cuando no se encuentren a la fecha muy difundidos. Los programas más avanzados permiten no solo encontrar palabras claves, sino identificar relaciones entre personas y secuencias de acontecimientos. Se prevé que las máquinas a partir de la revisión de miles de casos podrán recomendar estrategias judiciales, tal como lo haría un litigante experimentado. CARR, 2015: 138-139.

12 Vid. SCHAUER, 2013: 17-27.
} 
pares más aventajados. El asunto no es de extrañar pues la conducta humana —que, en último término, es lo que interesa al Derecho- no es fácil de medir, ni de reducir a regularidades. El análisis cualitativo que a diario se lleva a cabo por los jueces y los abogados se resiste a prescindir de los matices ${ }^{13}$. De esa manera, en ese mundo es difícil escapar de las prácticas propias de la ya aludida lógica del «a ojo de buen cubero».

Muchos jueces y abogados, sin embargo, no se sienten del todo cómodos operando en un mundo tan poblado de particularidades. Así, en la medida de lo posible, buscan algunas regularidades que faciliten las tareas que les corresponde ejecutar y/o disminuyan la responsabilidad (eminentemente moral) ${ }^{14}$ que viene aparejada por la toma de decisiones no derivables desde un patrón de comportamiento comunitariamente consensuado ${ }^{15}$.

Del instrumental utilizado por los jueces y los abogados, son los modelos conceptuales los que, probablemente, más se aproximan a una aplicación tecnológica ${ }^{16}$. Los modelos conceptuales son herramientas que sirven para organizar tareas de identificación y procesamiento de datos en casos concretos y, a la vez, para canalizar reflexiones teóricas. De esa manera, los modelos contribuyen a la solución de enigmas con un aceptable nivel de estandarización. La utilización de modelos conceptuales se traduce en que los problemas se simplifican, en términos de favorecer las comparaciones y/o igualaciones. El uso de los modelos conceptuales es, además, funcional a la generación de productos no dependientes de una manera especialmente fuerte de las habilidades personales de los sujetos que se enfrentan a distintos enigmas jurídicos. El precio a pagar, entonces, es un empobrecimiento de la realidad (se deja de poner atención en múltiples detalles) ${ }^{17}$ y a la vez, en una parcial reconfiguración de la profesión jurídica (más de técnica y menos de arte) ${ }^{18}$.

\subsection{El uso de los modelos conceptuales}

La elaboración de explicaciones que conectan acciones, eventos y/o fenómenos se ve beneficiada por una labor más/menos intensa de conceptualización que lleva a cabo

13 Esto explica, en parte, la resistencia hacia el uso de mecanismos de adjudicación aleatorios, aun cuando las diferencias respecto a lo que se pueda obtener si se recurre, en cambio, a un (costoso) análisis de la situación concreta, sea probablemente mínima. Vid. DuXBuRY, 1999: 137.

14 Whitman, 2008: $10 \mathrm{y} \mathrm{ss.}$

15 La comunidad de jueces, abogados y académicos —o si se prefiere, la cultura jurídica interna— no es tan homogénea al respecto. Así, mientras hay algunos que aspiran a la justicia del caso a caso y que, por tanto, no se sienten aproblemados si ante casos similares llegan a soluciones diferentes (en la medida que existan matices que los distingan); hay otros que tienden a la justicia de la regla, es decir, a la búsqueda de universalidades y, por tanto, no tienen reparos ante los intentos de simplificar los términos del debate fijando la atención en lo que consideran medular.

16 Una diferencia que parece insalvable entre las aplicaciones tecnológicas y los modelos conceptuales concierne a la evaluación de los resultados obtenidos, a partir del uso de cada uno de ellos. En el caso de las primeras, la evaluación se hace depender de su utilidad (sirve/no sirve); en cambio, en el caso de los segundos, se carece de criterios independientes de los procesos de construcción (se justifica/no se justifica, etc.). Lo expresado redunda en que las razones para el abandono o modificación de un modelo se determinarán en una importante medida por variables que podrían considerarse como políticas.

17 Cfr. Mosterín, 2013: 132.

18 Cfr. Twining, 1997: 63 y ss. 
una comunidad que ocupa un lugar de privilegio en lo que atañe a la producción y validación de un cúmulo de saberes en un campo de trabajo determinado ${ }^{19}$. Aquello implica ir mucho más allá de lo que es propio del sentido común. ${ }^{20}$ No es de extrañar, entonces, que quienes operan en el mundo del derecho coincidan —al menos, ocasionalmenteen formas de trabajo estandarizadas ${ }^{21}$ al momento de hacer frente a problemas concretos.

En el mundo del derecho se dispone de algunas teorías y modelos conceptuales útiles para enfrentar distintos enigmas que jueces, abogados y académicos deben gestionar y/o resolver ${ }^{22}$. El tipo de problemas a los cuales me refiero atañe, principalmente, al de las posibilidades de acoplar el mundo de las normas con el mundo de la experiencia. Dicho en otras palabras, se espera que los modelos conceptuales faciliten - directa o indirectamente - la operación de adscribir ${ }^{23}$ conductas (u omisiones) a determinados sujetos, en términos de que puedan hacerse calzar con la condición de aplicación de una norma jurídica. Esta tarea es muy importante, y de ella depende que la ideología de la aplicación de las normas jurídicas ${ }^{24}$ sea un proyecto viable y no, simplemente un artilugio retórico cuya dudosa utilidad estaría dada por el encubrimiento de la responsabilidad (moral/jurídica) de quienes crean soluciones ad hoc en cada nuevo caso que se les presenta ${ }^{25}$.

Los modelos conceptuales tienen como criterio de éxito primordial su efectivo uso en la elección de respuestas a problemas jurídicamente relevantes, como también en la explicación de los resultados alcanzados. Los modelos, entonces, no son descriptivos, es decir, no viene al caso evaluarlos desde la perspectiva de su verdad o falsedad ${ }^{26}$

19 Roberto TORRETTI ha llamado la atención sobre este punto en el campo de las ciencias. En sus palabras: «Si los filósofos naturales y los científicos, en vez de desarrollar sistemas intelectuales novedosos, se hubieran dado por contentos con el repertorio de nociones del sentido común precientífico, jamás habrían llegado a asociar fenómenos aparentemente tan dispares como las manzanas que caen, los satélites que orbitan y las galaxias que huyen, ni hacer que cada uno ilumine a los otros y les confiera una necesidad relativa. Aplicando su pensamiento innovador a los hechos observados, han logrado producir inferencias explicativas que de veras acrecientan nuestro entendimiento». TORRETTI, 2012: 73.

20 Respecto a las posibilidades que ofrece, por ejemplo, el uso de la inteligencia artificial, vid. TwINING, 2007: 169-185.

21 Las formas de trabajo estandarizadas, en ocasiones redundan en la consolidación de géneros textuales. Así, por ejemplo, pese a sus diferencias evidentes las sentencias penales dictadas por los tribunales chilenos conforman un género discursivo reconocible. AGÜERO, 2014: 15-18.

${ }^{22}$ Me refiero con ello, primordialmente, a las distintas ramas del derecho, en cuanto técnica para la fragmentación del campo de los juristas.

${ }^{23}$ Csaba VARGA distingue entre describir («está lloviendo») y adscribir («él lo hizo», «esto es mío»). Para lo primero cabe aplicar directamente el juicio verdadero o falso; en cambio, para lo segundo, se requiere de un marco institucional que coloca al sujeto en una determinada posición, desde la cual puede ser juzgado, principalmente, desde la perspectiva de su responsabilidad. VARGA, 1995: 126-127. Por cierto, para la decisión de adscribir conductas, algunas variables propias de un juicio puramente descriptivo pasan a ser relevantes (por ejemplo, que un sujeto haya muerto o que exista un objeto); lo que no obsta a que sea útil mantener diferencias claras entre ambas operaciones. Esto explica, por ejemplo, que para la adscripción sea muy importante contar con estándares de prueba que permitan zanjar definitivamente si un sujeto puede ser o no considerado como el autor de una conducta (en las descripciones suele no ser tan problemático dejar abiertos los enigmas). Vid. también WiTTGENSTEIN, 2004: 9.

24 Vid. nota 44.

25 Hay también modelos disponibles para resolver problemas lógicos de un sistema normativo. Su foco es la detección de lagunas, contradicciones y redundancias, lo que supone una simplificación de la tarea interpretativa que hace posible que distintos enunciados sean comparables. Vid. AlCHOURRón y BulYGIN, 1993.

26 Vid. COMANDUCCI, 2009: 77. Quien utiliza un modelo puede no creer lo que en él se plantea, basta que lo acepte por conducir a respuestas suficientemente buenas. MOSTERÍN, 2008: 224. 
(falta de ajuste a la realidad). Esto, por cierto, no obsta a que si se pretende operar adecuadamente en la cotidianeidad se requiera tener en cuenta cómo se entiende socialmente que son las $\operatorname{cosas}^{27}$. Los modelos conceptuales tampoco son directamente prescriptivos, es decir no constituyen pautas acerca de cómo debemos comportarnos, más allá de que se promueva su uso. Los modelos funcionan como reglas técnicas, esto es, proponen medios para alcanzar ciertos fines. Así las cosas, un modelo conceptual simplifica el mundo, por la vía de tener en cuenta algunas variables y silenciar otras, o bien de transitar desde una lógica que reconoce las categorías de «lo posible» o de «lo probable» hacia una lógica binaria que solo considera las opciones sí/no ${ }^{28}$; ello, en la medida, que sea instrumentalmente útil para alcanzar el fin propuesto.

Di Robilant distingue cuatro usos del término «modelo» en los escritos de filosofía del derecho. El primero refiere a un esquema representativo de un fenómeno de la realidad social; el segundo corresponde a un prototipo, a un ejemplo de un determinado fenómeno; el tercero da cuenta de un cierto esquema de comportamiento que debiera ser seguido; el cuarto a una construcción artificial para el análisis de un fenómeno de la realidad social ${ }^{29}$. El sentido en que aquí se usa el término modelo es el último de los señalados. De esta manera, el éxito o fracaso depende de las posibilidades de uso que el modelo propuesto ofrece.

\subsection{El concepto de «delito» como ejemplo de modelo conceptual ${ }^{30}$}

Como se sabe, los penalistas comprenden el delito como una «acción (u omisión) típica, antijurídica y culpable». Dicho modelo ha sido posible a base de teorizaciones (análisis cualitativo) y acuerdos alcanzados en el seno (vertiente dominante) de la respectiva comunidad disciplinaria. Un hito en cuanto a la definición de planes comunes (cohesión) de los penalistas fue la publicación de Dei delitti e delle pene de Beccaria ${ }^{31}$. El modelo conceptual, propiamente tal, fue propuesto por Ernst VON BELING a comienzos del siglo $\mathrm{XX}^{32}$ y se ha ido perfeccionando en su operatividad con el paso del tiempo. Así, el concepto de delito hace posible que enfrentados a ciertos enigmas, jue-

27 Para estos efectos, la idea de realidad y de cómo son las cosas está fuertemente determinada por la interacción cotidiana con los otros. El problema, entonces, no es tanto el de cómo son las cosas en sí, sino de las representaciones que permiten operar adecuadamente en contextos sociales de las cotidianeidad («experiencias cara a cara»). En estos se excluye de lo real, por ejemplo, a los sueños o a las experiencias reconocidamente simuladas, como lo sería la del teatro. Vid. BERGER y LuCKMAN, 2006: 34-63.

28 Esto, por ejemplo, es una función propia de los estándares de prueba que distribuyen ejemplares situados en la zona de penumbra de una categoría, hacia las respuestas probado/ no probado.

29 Di Robilant, 1968: 67 y ss.

30 Otro ejemplo de modelo conceptual exitoso se da respecto del concepto de acto jurídico de los civilistas. Probablemente, es la existencia de un modelo a cuyo uso se encuentran habituados los jueces y abogados lo que explica parte importante de las dificultades a las que se han visto enfrentados quienes han propuesto su reemplazo por el concepto (y teoría) del negocio jurídico.

31 Uno de los grandes méritos de la propuesta de BECCARIA (y también, la de FEUERBACH) es que fija la atención en una clase de problema que era posible de responder por la comunidad de los penalistas, esto es, ¿qué es delito? No ocurría lo mismo con otras interrogantes como era el caso de ¿qué es malo? o ¿qué es dañoso? Gunther JAKOBS con miras a identificar el factor determinante para atribuir un estatus científico a la ciencia penal —que él entiende que es la respuesta al problema de su legitimación— atribuye a FEUERBACH (y también a HEGEL) un papel clave para el nacimiento de la ciencia penal moderna. JAKOBS, 2008: 28-46. Agradezco a Luis Emilio ROJAs haberme señalado tempranamente el papel clave de FEUERBACH en el sentido indicado.

32 BELING, por cierto, perfecciona los desarrollos previos de otros penalistas. Así, se habla también de la teoría del delito de VON LiszT-BeLing. Vid. un panorama más completo en AmBOS, 2007. 
ces, abogados y académicos coincidan metodológicamente en la manera de construir una solución (lo harán en la tipicidad, en la antijuridicidad o en la culpabilidad). Una vez identificada la categoría apropiada, el penalista se sitúa en un ámbito más específico, como podría ser error de tipo, legítima defensa o inimputabilidad. Por cierto, los penalistas tienen discrepancias. Sin embargo, la fortaleza de los lazos que genera la aplicación del modelo común lleva a que sus explicaciones se hagan cargo de lo que dicen sus colegas para ciertos puntos específicos, independientemente de las discrepancias que puedan tener en los asuntos más gruesos del Derecho penal.

El modelo conceptual del delito implica una serie de simplificaciones respecto de las valoraciones de la conducta que se juzga. $\mathrm{O}$, lo que vendría siendo lo mismo, supone consensos respecto de lo que hay que considerar como irrelevante. Véanse un par de ejemplos para ilustrar lo señalado:

a) Al estipular que la tipicidad es condición para la existencia de un delito o cuasidelito (categorías de las que se hace depender la legitimidad de la aplicación de penas penales), se declaran irrelevantes la peligrosidad o el parentesco como razones para castigar ${ }^{33}$. De la misma manera, al exigir la concurrencia de dolo o culpa a los efectos de calificar como delito doloso o delito culposo, se trazan fronteras con pretensiones de nitidez entre lo doloso ${ }^{34}$, lo culposo y lo fortuito, aun cuando nuestras experiencias se resistan a ser descritas recurriendo a esas categorías tan toscas (la intención, la negligencia y el acaso son graduables), las cuales en muchos casos se superponen.

b) $\mathrm{Al}$ asociar la imputabilidad a una determinada edad se declara irrelevante algo obvio - y que sí tenemos en cuenta en otras circunstancias de la vida—, esto es, no todos maduramos al mismo tiempo, ni tampoco alcanzamos los mismos niveles de comprensión acerca de lo injusto de nuestras acciones y omisiones.

\section{LA DECISIÓN DE LOS HECHOS COMO PRINCIPAL PRODUCTO DEL MODELO CONCEPTUAL}

El dominio de conceptos disciplinarios — unido al desarrollo de competencias analíticas y estratégicas - constituye una de las condiciones primordiales para que jueces y abogados aborden exitosamente distintos desafíos que se les plantean en los procesos judiciales ${ }^{35}$. La atención, en lo que sigue, se dirigirá hacia el uso de los conceptos probatorios. Los conceptos desempeñan un rol determinante en la forma en que los participantes fijan su atención e interpretan los acontecimientos, ya sea en la fase de investigación como en el juicio mismo ${ }^{36}$. Asimismo, los conceptos

33 Como se sabe, aquello no ha sido históricamente así.

34 Para gestionar algunos casos dudosos se crean las subcategorías de dolo de las consecuencias seguras y eventual. Ellas, a su vez, generan nuevos problemas bastante difíciles, aunque algo más manejables.

35 TORRETTI, 2012: 60-66 (especialmente).

36 Además de llamar la atención respecto a los usos que hacemos del lenguaje (utilizando su conocida metáfora de la caja de herramientas), WITTGENSTEIN subraya el papel de los conceptos como instrumentos para hacer ciertas cosas. Dice textualmente: «Los conceptos nos conducen a investigaciones. Son la expresión de nuestro interés, y guían nuestro interés». WITTGENSTEIN, 2004: 359. Sobre relaciones entre significado y empleo de las palabras, vid. también WiTTGENSTEIN, 2004: 193-199. 
orientan el uso que conviene dar a los recursos probatorios disponibles, llegado el momento de construir o de destruir argumentos. En pocas palabras, los conceptos determinan, en una importante medida, cómo observan ${ }^{37}$, cómo piensan ${ }^{38}$ y cómo argumentan los jueces y los abogados. Así, por ejemplo, ante un sujeto sentado en una silla que emite sonidos en lengua castellana y gesticula con sus manos, es previsible que tanto jueces como abogados presten atención más o menos a lo mismo y, a la vez, se desentiendan, más o menos, de iguales $\operatorname{cosas}^{39}$. La confluencia perceptual e interpretativa entre los participantes no depende de las propiedades de las cosas o de los acontecimientos en sí. Al realizar actos observacionales o inferenciales, los jueces y los abogados tienen en cuenta conceptos tales como relevancia o estándar de prueba. De esta manera, cada oración pronunciada por los testigos será escrutada a la luz de la relevancia que quepa asignarle, tanto para la corroboración o refutación de la conjetura que se debate, como por su utilidad para dar (o no) por superado el estándar de prueba aplicable. Sin esos conceptos, las actuaciones de los abogados y de los jueces serían muy distintas. Un fenómeno similar ocurre al momento de formular los alegatos de clausura (o de dictar la sentencia). Conceptos tales como valor probatorio, credibilidad y estándar de prueba determinarán lo que los abogados y jueces competentes usarán o dejarán de lado a partir de las distintas aseveraciones que formule un testigo.

La mayoría de los conceptos útiles para la gestión de las pruebas y argumentos que se producen en los procesos judiciales son comunes a los que se usan en otros contextos (no jurídicos) en que, también, se trata de probar o de refutar conjeturas ${ }^{40}$. Según es fácil advertir, el significado que se atribuye a varios de ellos no experimenta cambios considerables dependiendo del contexto en que se opere. Hay otros, en cambio, que se encuentran más afinados (o simplificados) en los textos jurídicos, en las sentencias, o en las conversaciones entre especialistas. Un listado incompleto, pero que da cuenta de la mayoría de los problemas que se presentan en el contexto probatorio, sería el siguiente: admisibilidad, carga de la prueba, estándar de prueba, hecho (probado), medio de prueba, pertinencia, presunción, relevancia y valoración de la prueba. A ellos debiesen sumarse otros tales como credibilidad, fuerza probatoria (o valor probatorio) y justificación (fáctica), los cuales sin perjuicio de ser especificaciones de otros más genéricos (valoración de la prueba), su análisis por separado resulta de bastante utilidad. Un caso similar se daría con el concepto de hechos a probar (conjetura) estrechamente

37 Lo expresado es una manifestación del fenómeno que HANSON identificó como de «carga teórica de la observación», es decir, aquello que vemos se encuentra moldeado por nuestro lenguaje y, en general, por nuestros conocimientos previos. HANSON, 1977: 99. Un anticipo de ello puede verse en KANT, 1973: 1. ${ }^{\mathrm{a}}$ parte, párr. 8, 192; BENTHAM, 1971: 49-53.

38 Vid. TORRETTI, 2012: 84 y ss.

39 En otras palabras, los abogados y los jueces se focalizarán en ciertas partes del relato y no en otras; se preocuparán en los gestos del testigo ante determinadas preguntas y no en otras, etcétera. Las coincidencias, por cierto, no serán absolutas.

40 La coincidencia parcial entre las tareas que llevan a cabo los juristas, los analistas, los historiadores, etcétera lleva a que sea más que sensato fijar la atención en una lógica de las pruebas independiente de las reglas específicas estipuladas en cada sistema jurídico. El punto es importante ya que obliga a los juristas a permanecer atentos a desarrollos que ocurren en otros campos de trabajo. Un buen ejemplo de los usos que pueden darse de los avances externos puede verse en ANDERSON et al., 2015:33-78. Sobre el giro que se detecta en los artículos publicados en revistas norteamericanas, desde lo doctrinal hacia lo interdisciplinario, vid. PARK y SAKS, 2006: 952. 
ligado al juicio de pertinencia ${ }^{41}$. Hay por cierto, muchos otros conceptos que podrían calificarse como secundarios ya que están en una relación de dependencia con algunos de los conceptos ya señalados, como sería el caso de convicción, corroboración, interrogatorio, perito, prueba ilícita, sana crítica, testigo, etcétera ${ }^{42}$.

Las posibilidades de asociación entre los conceptos son múltiples, aunque limitadas. Así, por ejemplo, el juicio de admisibilidad — que es determinante para la aceptación de algunos medios de prueba y la exclusión de otros- presupone un análisis de relevancia, el que, a su vez, requiere de un juicio de pertinencia. Hay otras relaciones que son más problemáticas, como sería el caso que se da entre presunción y fuerza probatoria. En lo que sigue, se explica por qué el concepto de hechos (probados) debiese constituir la base del análisis y cumplir funciones ordenadoras del resto.

\subsection{Algunas cuestiones a aclarar respecto de los dispositivos factuales}

Como se sabe, la influencia de los sistemas jurídicos en la vida cotidiana depende, en gran medida, de la clase de respuestas que los órganos de adjudicación habitualmente suministran. Lo expresado redunda en un elevado interés ( $y$, a la vez, dificultad) de los juristas para trazar una distinción entre validez y eficacia normativa (o lo que vendría siendo casi lo mismo, entre el derecho en los libros y el derecho en acción). La brecha entre ambas categorías no debiese ser demasiado ancha ya que, en caso contrario, sería expresiva de una patología del sistema normativo que llevará a fin de cuentas a plantearse, ya sea si lo dicho en los libros o bien, si las prácticas de los órganos autoritativos, constituyen realmente derecho ${ }^{43}$.

Una forma de mantener controlada la brecha entre validez y eficacia supone suscribir - y esforzarse en actuar conforme a- lo que WRÓBLEWSKI llamó la ideología de la aplicación judicial del Derecho ${ }^{44}$. Para ello resulta esencial la legitimación de los procesos de identificación y atribución de significados a las disposiciones jurídicas, como también la validación de las rutinas de adscripción de conductas en sujetos en quienes se harán recaer determinadas consecuencias jurídicas ${ }^{45}$. Aquello merece ser observado con atención, pues los órganos de adjudicación cuentan con facultades tanto para fijar autoritativamente el derecho en el caso concreto ${ }^{46}$, como también para

${ }^{41}$ Parafraseando a HANSON (vid. nota 37), se ha sostenido que «en el área de nuestro interés, tendría que decirse que los enunciados fácticos corren, además, el riesgo de estar cargados de derecho». ANDRÉs, 1992: 265. La afirmación es ilustrativa respecto de lo que se espera con la prueba de los hechos.

${ }^{42}$ Un glosario bastante completo y que da cuenta además de una terminología útil para los efectos de ordenar las piezas de prueba (bajo una lógica sofisticada) puede verse en ANDERSON et al., 2015: 445-451.

43 Vid., por todos, Holmes, 2012: 59 y ss.

44 Esto ocurre de manera especialmente fuerte en la categoría que el mismo WRÓBLEWSKI llama ideología de la decisión vinculada y, en menor medida, en la de la ideología de la decisión legal y racional. No ocurre, en cambio, si se suscribe la ideología de la libre decisión. WRÓBLEWSKI, 1989: 67-84.

${ }^{45}$ Lo expresado es una manifestación de que lo que hacen los órganos de adjudicación no se limita a imponer cargas u otorgar beneficios, sino que supone realizar otras tareas aledañas de carácter no prescriptivo y que culturalmente se entienden necesarias para la adjudicación. Esto lleva a HART a sostener que lo que impulsa a centralizar la fase de adjudicación en órganos dotados de competencia no se reduce a interrogantes acerca de qué hacer con un sujeto sobre el que recae una determinada acusación, sino principalmente a si ha habido una violación a una norma jurídica. Vid. HART, 1995: 113-122.

46 Esto, por cierto, no exonera al tribunal de recibir críticas por la elección de textos normativos o por la interpretación que de ellos ha realizado. 
decidir los hechos ${ }^{47}$. Para dar cuenta de las relaciones entre las normas y las conductas (acoplamientos) es usual recurrir a expresiones tales como «subsunción»o «justificación interna» ${ }^{48}$. Aquello facilita que dicho tramo del razonamiento sea susceptible de reconstruirse bajo una estructura propia de la lógica deductiva ${ }^{49}$. Tanta sincronía, sin embargo, debe mirarse con sospecha. Su aceptación sin las debidas precauciones incide en que los problemas serán transferidos hacia el «patio trasero» del razonamiento, esto es, a la justificación externa ${ }^{50}$.

A diferencia de lo que ocurre con las normas cuyo significado se hace depender de debates que se dan en distintos foros (revistas académicas, seminarios, aula de clases, estudios de abogados, sentencias, etc.), los hechos constituyen un producto que depende fundamentalmente de lo que suceda en cada proceso judicial. Ni el proceso formativo de los futuros jueces y abogados, ni el nivel de producción científica en asuntos probatorios resulta equiparable al que es propio de las cuestiones que se relacionan con la validez e interpretación de formulaciones normativas ${ }^{51}$. Los problemas de prueba desencadenan, principalmente, tensiones y desacuerdos en la fase de validación de aquellas conjeturas que adscriben conductas («hechos a probar») sobre ciertos sujetos. El resultado procesal, se supone, dependerá, por una parte, de lo manifestado a través de los medios de prueba disponibles; y por la otra, de lo que cabe inferir desde diversas generalizaciones cuyo uso está procedimentalmente previsto ${ }^{52}$.

Dejando de lado una serie de restricciones que afectan al proceso probatorio ${ }^{53}$ la pregunta que, en principio, pareciera pertinente contestar para los efectos de conferir el estatus de «probadas» a una o más conjeturas — presentadas bajo la etiqueta de los hechos a probar-asume formas tales como: ¿qué ha pasado o ¿cómo es el mundo? ${ }^{54}$. La razón aparenta ser de Perogrullo: las conductas que cabe adscribir a las personas deben ser restringidas a aquellas que efectivamente han ejecutado ${ }^{55}$. Bajo tal supuesto, la dirección de ajuste esperada sería desde las palabras al mundo (el mundo permanece invariable; las palabras, en cambio, estarán llanas a modificarse cada vez que sea necesario).

Lo que sucede en los procesos judiciales difiere, sin embargo, en no poco con las expectativas recién planteadas. Pese a los esfuerzos desplegados por sus distintos

47 La distinción entre quaestio juris y quaestio facti no es en la práctica tan nítida como la que aquí se presenta. Vid., entre otros, Allen y PARDO, 2003; 1769 y ss.; Fox, 1899: 551.

48 WRÓBLEWSKI, 1974: 33-46.

49 La decisión, por cierto, es siempre un acto de voluntad. De lo que se trata cuando se habla de esta manera es de reconstruir lo realizado en términos de verificar si la conclusión a la que se llegó era o no lógicamente derivable de sus premisas. AlCHOURRÓn y Bulygin, 1991: 303-304.

50 Sin perjuicio de lo señalado, la subsunción puede prestar ayuda en el control del razonamiento si se entiende como una reconstrucción posible que exige atención a la construcción de sus premisas. Vid. MACCORMICK, 2007: 321-334.

51 Coloma, 2016a: 56-67.

52 Las generalizaciones son necesarias aunque peligrosas, dando lugar a una serie de desacuerdos al momento de utilizarlas. ANDERSON et al., 2015: 321-350. Aquello se traduce en una serie de perplejidades, por ejemplo, respecto a lo que implica valorar la prueba conforme a la sana crítica, o a nivel de mayor detalle, a cómo se reconoce (o construye) una máxima de la experiencia. COLOMA y AGÜERO, 2014: 673-703.

53 Vid., por ejemplo, GASCÓN, 1999: 125 y ss.; y LAUDAN, 2013: 173 y ss.

54 Dice WRÓBLEWSKI: «La decisión de la prueba es la constatación judicial de que el hecho F existe en el tiempo t y en el lugar p. En la aplicación del derecho se deben hacer constataciones de este tipo fundadas en las pruebas». WRÓBLEWSKI, 1989: 70.

55 Así, por ejemplo, entiende TWINING que ocurriría con la tradición racionalista en la que se inscribe una larga lista de autores como Bentham y Wigmore. Twining, 1990: 73. 
participantes, al término de un proceso las preguntas de ¿cómo es el mundo? o ¿qué ha pasado? no se encuentran en condiciones de ser respondidas en toda su complejidad $^{56}$. Aquello es consecuencia —entre otras cosas- de que: i) los recursos probatorios (pruebas y argumentos) que se encuentran en condiciones de ser provistos, ya sea por las partes o por el Estado, son limitados; ii) el tiempo del cual se dispone para zanjar controversias es finito, y iii) los problemas a los que se enfrentan los tribunales en un elevado número de casos no son reducibles a regularidades (conducta humana). Así las cosas, el contexto en el que se mueven los tribunales es el propio de la toma de decisiones bajo incertidumbre o, en el mejor de los casos, bajo riesgo ${ }^{57}$.

William Twining distingue cinco perspectivas que desafían a las tradiciones racionalistas de la prueba. Entre ellas, por ejemplo, se encuentra la de los escépticos filosóficos que ponen en duda la posibilidad de determinar válidamente cómo es el mundo (el conocimiento, los argumentos racionales o los valores objetivos constituyen una imposibilidad); la de los escépticos ideológicos que cuestionan la neutralidad de las investigaciones (las perspectivas racionalistas ocultan propósitos represivos, etc.); e, incluso, la de quienes cuestionan la factibilidad de contar con instituciones, procedimientos y reglas que maximicen la rectitud de las decisiones ${ }^{58}$.

Una explicación de la pervivencia en el tiempo de la brecha existente entre las expectativas cognoscitivistas que recaen oblicuamente ${ }^{59}$ sobre el sistema de adjudicación y aquello a lo que este se encuentra en condiciones de proveer, pudiera ser el siguiente: La pregunta ¿qué es lo que ha sucedido? o ¿cómo es el mundo? no admite ser respondida, al menos en un sentido fuerte. En vista de ello, es sustituida por otras respecto de las cuales los jueces sí pueden hacerse cargo ${ }^{60}$. La sustitución que se lleva a cabo no es transparente, es decir la nueva pregunta se presenta como un equivalente a la original con lo cual no es claro lo que se ha perdido con la transformación realizada ${ }^{61}$. Las movidas de los juristas suponen una distinción inicial entre diferentes

56 En ese sentido, CELANO sostiene que los jueces tienen una obligación de «buscar la verdad», pero no de encontrarla. CELANO, 1995: 146.

57 La explicitación de estándares de prueba, por ejemplo, constituye un reconocimiento de que la pregunta que deben responder los tribunales a los efectos de decidir si los hechos están probados no es (al menos en un sentido fuerte) si cierto evento ha sucedido o no.

58 TwINING, 1994: 131-133.

59 Utilizo la expresión «oblicuamente» para matizar las expectativas cognoscitivistas. Los autores que las defienden rara vez desconocen las restricciones a las cuales estas se encuentran expuestas. En ese sentido, no son expectativas radicales, sino moderadas.

60 En un libro exitoso, el matemático George PÓLYA aconseja que si uno no puede resolver un determinado problema debiera comenzar por hacerse cargo de otro (relacionado) que sí le resulte accesible (PóLYA, 1973: xvii). Los psicólogos Amos TVERSKY y Daniel KAHNEMAN han transferido dicha sugerencia hacia otros contextos para así dar cuenta de un mecanismo al que habitualmente se recurre para no tener que abstenerse de dar respuesta a distintos enigmas que se plantean, en situaciones de escasa información. Dice KANNEMAN: «Nos preguntábamos cómo la gente puede hacer juicios de probabilidad sin conocer con precisión lo que es la probabilidad. Concluimos que la gente tiene que simplificar de algún modo esta tarea imposible, y nos pusimos a buscar cómo lo hace. Nuestra respuesta fue que cuando se le pide juzgar probabilidades, la gente realmente juzga algo y cree que ha juzgado probabilidades». KAHNEMAN, 2012: 132-135. Un análisis de la epistemología de la producción de los hechos en contextos judiciales puede verse en Ho, 2010: 85-171.

61 En la vida cotidiana preguntas tales como: ¿qué ha pasado?, son transformadas por el interlocutor por otras más sencillas, como sería el caso de: ¿qué recuerdo haber observado?, ¿qué me ha dicho la gente que ha sucedido? o ¿cómo puedo explicar que el vidrio del baño se haya trizado? Por cierto, el interlocutor, rara vez, hará explícita la sustitución. A su vez, quien formuló la pregunta original debiese estar consciente de que una pregunta tan compleja como podría llegar a ser: ¿qué ha pasado?, será sustituida por su interlocutor. 
clases de hechos, lo que da también espacio a diferentes formas de validación. Así, la pregunta original ¿qué es lo que ha pasado?, muta en diferentes preguntas sustitutivas. Las diferencias resultan explicables dado que en cada categoría creada hay diferentes valores en juego que debilitan en distintos niveles las pretensiones cognoscitivas. Así, las preguntas sustitutivas aluden a circunstancias variadas, esto es, al silencio de los litigantes, al acuerdo entre ellos, a la existencia de presunciones legales y a la cantidad y calidad de las pruebas disponibles para el caso concreto.

Para aludir a cada categoría utilizaré la locución «dispositivo factual». Con ello quiero enfatizar que al otorgarse el estatus de «hechos» a distintos enunciados, lo que se busca es disponer de un soporte argumentativo para una decisión que implica cargas y/o beneficios para las partes en conflicto. La palabra dispositivo ${ }^{62}$ resulta bastante neutral para los efectos señalados, la que unida al calificativo de «factual» da cuenta de que dicho dispositivo permite adscribir conductas. Acorde con lo indicado, las categorías de hechos ${ }^{63}$ que se presentan en las sentencias serían las siguientes:

a) Dispositivo factual de lo no problematizado (Hechos no problematizados). Este dispositivo se hace cargo de la pregunta: ¿Hay o no conflicto entre las partes respecto de las conductas que pretenden adscribírseles ${ }^{64}$ ? De acuerdo a este dispositivo, si las partes nada hacen, entonces es válido adscribirles las conductas propuestas, ya sea en la conjetura definida por el tribunal (hechos a probar), o bien en el relato presentado por una o ambas partes por separado.

b) Dispositivo factual de lo consensuado (Hechos consensuados). Este dispositivo es útil para hacer frente a la pregunta: ¿Hay acuerdo expreso entre las partes respecto de la conducta que cabe adscribir a cada una de ellas? Si las partes convienen las conductas que deben serles adscritas, entonces aquellas adquieren el estatus de «hechos» ${ }^{65}$.

Los dos dispositivos recién indicados se construyen interviniendo en las cargas de alegar que el legislador impone sobre las partes ${ }^{66}$. En rigor, la circunstancia de que una o ambas partes no controvierta una determinada forma de reconstruir acciones no dice

62 Según el diccionario de la Real Academia de la Lengua Española, uno de los significados de la palabra «dispositivo» es «mecanismo o artificio para producir una acción prevista». La definición viene bien para lo que aquí se quiere comunicar.

63 Agradezco a Claudio AGÜERO sugerirme la distinción que a continuación se realiza en el texto principal. Las tres primeras categorías dan cuenta de hechos que los procesalistas sostienen que no requieren probarse. Sus clasificaciones, en todo caso, suelen ser más detalladas. Vid. CouTuRE, 2014: 183-194.

${ }^{64} \mathrm{La}$ pregunta que aquí se formula podría ampliarse si con ella se quiere dar un cuenta de una categoría de hechos intermedios - a la que brevemente me refiero más adelante- como lo es la de los hechos públicos y notorios. En tal caso podría preguntarse si hay o no discrepancias sociales respecto de acontecimientos que han podido ser observados y/o discutidos por una cantidad importante de sujetos. En caso de recibir respuesta negativa podría pensarse en un dispositivo factual de lo público y notorio.

65 En otros contextos, los consensos o la inexistencia de razones para problematizar también son importantes para dar cuenta de lo que se reconoce como un saber (o en lo que aquí interesa «hechos»). WITGENSTEIN da el siguiente ejemplo: «Imaginemos que el alumno preguntara en realidad: ¿Existe también la mesa cuando me doy vuelta o cuando nadie la ve? En este caso, ¿debería el maestro tranquilizarlo y decirle: “¡Por supuesto que existe!"? Es posible que el maestro se impaciente un poco, pero pensará que el alumno dejará de hacer tales preguntas. Es decir, el maestro tendría la sensación de que esta no es una pregunta en absoluto legítima». WITTGENSTEIN, 2000: 40c.

66 Siguiendo a Ronald ALLEN, «[1] as cargas de alegar especifican las condiciones bajo las cuales las pretensiones fácticas/jurídicas serán consideradas para su inclusión en un litigio». ALLEN, 2013: 41. 
demasiado en términos de que las cosas hayan ocurrido de una cierta manera ${ }^{67}$. Sabemos que el silencio de una o ambas partes puede obedecer a una multiplicidad de razones escasamente vinculadas a que «la realidad» haya sido de una cierta manera y no, de otra. En ocasiones, las partes no alegan por pereza, porque los costos económicos de hacerlo son elevados, por temor a desagradar, u otras razones por el estilo. De este modo, el consenso de las partes tiene múltiples orígenes que no siempre son acordes a lo que cabe entender como epistémicamente validado ${ }^{68}$. Hay, por cierto, restricciones a esta forma de construir dispositivos factuales que apuntan a que, en determinadas circunstancias, el Estado no está dispuesto a correr el riesgo de que las disposiciones jurídicas sean burladas. Así, por ejemplo, hay procedimientos en que no se acepta que las partes negocien hechos y, también algunos en que los acuerdos requieren del visto bueno de un juez ${ }^{69}$.

c) Dispositivo factual de lo presumible (Hechos presumidos). Este dispositivo se hace cargo de la pregunta: ¿Hay hechos (conductas) que el legislador autorice que se presuman desde ciertas premisas? Si el legislador establece que de la existencia de ciertos hechos pueden/deben colegirse otros y se aprueba la existencia de tales hechos iniciales, entonces aquellos que sean derivados (presumidos) adoptarán la forma de dispositivos factuales.

Salvo en el caso de las presunciones de derecho (no admiten prueba en contrario $\mathrm{y}$, en rigor, corresponden a una cierta manera de formular reglas), el dispositivo factual de lo presumible se utiliza para alterar cargas de persuasión y de producción de pruebas. Esto implica que si la parte que soporta las cargas de producción y de persuasión nada hace, el hecho respectivo se dará por probado (lo cual no ocurriría en los casos de inexistencia de la presunción $)^{70}$.

d) Dispositivo factual de lo probado (Hechos probados). Este dispositivo hace frente a la pregunta: ¿Hay pruebas suficientes que validen la conjetura de que uno o más sujetos ha(n) realizado determinada(s) acción(es)? ${ }^{71}$. Si tales pruebas son calificadas institucionalmente como suficientes, entonces serán hechos los que el juez esté autorizado a inferir desde las pruebas rendidas y de las generalizaciones que sean aplicables.

Este dispositivo factual no difiere demasiado de los hechos que se validan en otros contextos cuando se trata de sortear la pregunta acerca de ¿cómo es el mundo?

67 TARuffo, 2008: 129-151. Vid. especialmente las páginas 148-150 en que llega a la misma conclusión aquí indicada (aunque por una vía argumental diferente), en cuanto a que, a fin de cuentas, lo que está en juego son las cargas de probar.

68 El reconocimiento de estas dos categorías de dispositivos factuales resulta más propia de un Estado escasamente perfeccionista, antes que de uno preocupado por imponer planes de vida a los ciudadanos. El primero reconoce a las partes un rol clave para la construcción de los hechos, incluso si aquello conduce a un alejamiento de lo que se entiende como probado en otros contextos. Vid. DAMASKA, 2000: 193-197. chileno)

${ }_{69}$ Así, por ejemplo, ocurre en el procedimiento abreviado (arts. 406, 409 y 410 del Código Procesal Penal

70 Un análisis más detallado puede verse en AlLEN, 2013: 44-48. Vid. también SCHAUER, 2013: 228-232, quien entiende el problema de las presunciones como un asunto de carga de la prueba.

${ }^{71}$ La pregunta va acompañada de una de carácter negativo y que apunta a la insuficiencia de las pruebas que refuten la conjetura. La determinación de la suficiencia probatoria tiene en cuenta aspectos tanto cuantitativos como cualitativos. Cfr. FERRER, 2005: 27-38. 
Los elementos más obvios de nuestras creencias mediante los cuales hacemos frente (indirectamente) a la pregunta de ¿cómo es el mundo? son: i) un contenido (lo que se cree); ii) una actitud que puede tener distinto grado de intensidad y que puede ir desde la certeza hasta un punto ligeramente superior al de la no creencia, y iii) un conjunto de razones para la creencia. ${ }^{72}$ Los sistemas jurídicos se hacen cargo de estos tres elementos ya que en algún momento del proceso se define: i) la conjetura desde la que se extrae en último término el contenido proposicional de los hechos; ii) la intensidad de la convicción o de los soportes evidenciales ${ }^{73}$ con que cuenta el tribunal en términos de definir si un hecho está probado (cumple) o no probado (no cumple), y iii) la clase de razones que pueden presentarse como soporte de los hechos probados (deben derivarse de pruebas admisibles, valoradas conforme a la sana crítica, etc.).

De las distintas categorías de hechos que se incorporan en las sentencias la que resulta más desafiante desde una perspectiva conceptual y metodológica - $\mathrm{y}$, por regla general, la que es más relevante en la práctica- es la de hechos probados. A esta categoría refiere el acápite siguiente ${ }^{74}$.

Un punto del que no me haré cargo, pero que al menos será útil dejar anunciado se relaciona con algunas ambigüedades de la palabra «hechos» utilizada en la argumentación que es propia de los procesos judiciales. Aparte del sentido que aquí interesa —el cual supone su directa relación con una o más normas que estipulan las consecuencias que se hacen recaer sobre el demandado o acusado-, se puede hablar de hechos para dar cuenta de otros enunciados que no adscriben directamente conductas, pero fijan sus presupuestos ${ }^{75}$. Así por ejemplo, hechos tales como Edipo mató a su padre Layo, o Antonio está ocupando sin título alguno la casa X de Próspero, admiten, respectivamente, ser acopladas con el tipo penal de parricidio y con la norma que estipula la reivindicación. Aun cuando están formulados parcamente, es fácil observar que suponen otros hechos tales como «Layo ha muerto», «Edipo es hijo de Layo», «Antonio ocupa la casa X», o «Próspero es dueño de la casa $X »$. Tales enunciados no adscriben conductas o si lo hacen, no son de aquellas que admiten acoplarse con normas jurídicas desde las que se extraerá la solución que interesa. Estos hechos también son producidos en las sentencias (en ellas se dan por probados) y, en términos generales, cabría llamarlos hechos intermedios. Incluso es posible que se den por probados estos hechos sin que en la respectiva sentencia se lleguen a adscribir conductas, lo que ocurriría, por ejemplo, si se da por probado el hecho punible, pero no la participación del acusado ${ }^{76}$.

72 PEPPER, 1942: 11-12.

73 La actitud requerida de parte de los tribunales de justicia pueden depender tanto de la subjetividad de sus miembros (por ejemplo, íntima convicción), como de la aceptabilidad de la conjetura en conformidad a esquemas culturalmente validados (dentro de estos últimos podría situarse el uso del cálculo probabilístico). Vid. LAUDAN, 2005: 98 y ss.

${ }_{74}$ De aquí en adelante, cuando se hable de los hechos me estaré refiriendo a los hechos probados.

75 Más aún, entre jueces y abogados también habría un tercer sentido en que se podría hablar de hechos. Su relevancia es menor y podría denominársele como hecho-acontecimiento. Respecto de ellos es indiferente que alguien lo sostenga e, incluso, que los advierta. Por ejemplo, son hechos-acontecimientos los sonidos que emite el testigo y que el auditorio interpreta como una respuesta, como también que el testigo haya dado 25 pasos entre el umbral de la puerta y la silla donde se sentó. El hecho-acontecimiento es considerado como «lo dado».

76 Esto se puede hacer calzar con la distinción que autores como T. ANDERSON, D. SCHUM y W. TwINING - siguiendo a J. H. WIGMORE- hacen entre probandum intermedio, penúltimos probanda y probandum último o final. ANDERSON et al., 2015: 449. 


\subsection{El concepto de hecho como concepto ordenador del derecho probatorio}

Los hechos (probados) son el producto (principal) extraíble desde las pruebas rendidas en un proceso judicial y de la actividad argumentativa que en él se produce. Al adscribirse conductas a determinados sujetos (decisión de los hechos), los tribunales se encuentran autorizados/obligados a vincularlos autoritativamente con una o más normas jurídicas. De esta manera, los hechos son claves para justificar el razonamiento práctico de los jueces. Antes de que se dicte una sentencia es institucionalmente aceptable que coetáneamente se afirme, por parte de algunos, que Aurora adeuda 500.000 dólares a Victoria y, por parte de otros, que Aurora nada adeuda a Victoria. Ambas afirmaciones, prima facie, son merecedoras del mismo respeto. En cambio, dependiendo de lo que se haya dado por probado, una vez dictada la respectiva sentencia, solo se considerará seriamente, ya sea que Aurora adeuda o que no adeuda cierta cantidad de dinero. Esto es importante, ya que solo a partir de ese momento Aurora pasará a desempeñar una posición jurídica que es propia de sujetos que adeudan $— \mathrm{o}$ no adeudan - a otro una determinada cantidad de dinero.

La adscripción (o negativa de adscripción) de una conducta no garantiza que los hechos en un juicio sean resistentes a intentos de falsación provenientes desde fuera del sistema jurídico. Así, la garantía que la prueba de los hechos otorga es intra-sistémica, lo que no libera al proceso judicial de la necesidad política de ser deferente, en la medida de lo posible, con lo epistémicamente exigible en otros contextos (prestigiosos). Esta expectativa de deferencia, sin embargo, no es suficiente como para poner en duda el estatus de hecho probado/no probado de un determinado enunciado, mientras se opere en el sistema jurídico.

Pese a su relevancia, el concepto de «hecho probado» o más sencillamente el concepto de «hecho» ha sido escasamente problematizado dentro de la comunidad de los juristas. El concepto de «hecho» tiene un carácter eminentemente operacional. De esta manera, su comprensión se hace depender de las tareas que permita llevar a cabo en el contexto de un proceso ${ }^{77}$. Más concretamente, los hechos importan en la medida que sirven de soporte a argumentos útiles para la distribución (o negación) de cargas y/o beneficios. Así las cosas, los hechos (en las sentencias) ${ }^{78}$ son artefactos lingüísticos ${ }^{79}$ cuya función es la adscripción de acciones u omisiones jurídicamente relevantes sobre uno o

77 Este punto es clave para comprender mis diferencias con conceptualizaciones como las que, por ejemplo, propone Daniel GONZÁLEZ LAGIER. Él advierte el carácter complejo de los hechos, en cuanto articulan elementos observacionales y normativos. Desde su perspectiva, la tarea interpretativa opera sobre datos sensoriales, y se encuentra determinada de manera gravitante por los conceptos utilizados. GONZÁLEZ, 2013: 77-79. De esta manera - a diferencia de lo aquí sugerido- para entender los hechos no se asigna un valor central al acoplamiento que se espera lleguen a tener los hechos con las normas jurídicas que pretenden aplicarse, pues el foco está puesto en las posibilidades que ofrecidas por los datos sensoriales pasados por el tamiz de las interpretaciones.

78 Al hablar de hechos en las sentencias me hago cargo de ambigüedades de dicha palabra en el contexto de un proceso judicial. Así, por ejemplo, en las distintas fases del juicio se habla de los hechos queriendo referirse con ellos a diferentes cosas. Hablo en la mayor parte de este artículo de hechos a secas, pues aquellos son los ejemplares más importantes en el proceso judicial y en la reconstrucción del razonamiento jurídico.

79 Respecto de la discusión acerca de qué tipo de enunciado son los hechos en la sentencia, los entiendo como eminentemente constitutivos, aclarando que dicho carácter no los exime de un juicio crítico cuando no se han satisfecho (pudiendo haberlo hecho) exigencias que se entienden más propias de los enunciados descriptivos. Cfr. FERRER, 2005: 19 y ss. 
más sujetos. Dicha condición es común a los distintos dispositivos factuales que previamente se han identificado en este texto. Como ya ha sido dicho, la forma de validación de cada uno de ellos es diferente, siendo de especial interés la categoría de los hechos probados. Esta última, hace depender el otorgamiento del estatus de hecho probado a los resultados de un proceso de contrastación sobre una conjetura (factum probandum) que adscribe conductas jurídicamente relevantes a los partícipes de un juicio ${ }^{80}$.

Uso la expresión artefacto lingüístico con miras a enfatizar, por una parte, que los hechos de la sentencia (los que se califican jurídicamente) no corresponden a un fragmento de la realidad o a algo que ocurrió, como tampoco a un fragmento específico del texto de la sentencia, aun cuando se requiera de este último para su constitución. La noción de artefacto da cuenta de la funcionalidad del dispositivo decidido por los tribunales de justicia (sirve para hacer cosas), admitiendo ser reconstruido de distintas maneras por sus intérpretes (no es el símbolo en sí, sino su significado). Su carácter constitutivo incide en que los hechos en la sentencia se entiendan como definitivos, a pesar de que fuera del espacio de lo jurídico pueda no quedar del todo resuelto el problema de la determinación de lo que habría ocurrido ${ }^{81}$.

Es usual que en las sentencias los hechos se expresen mediante un relato que un intérprete competente debiera ser capaz de reconstruir en términos de verificar si calza o no con la norma aplicada en la misma sentencia. Cabe advertir, eso sí, que no es infrecuente que el aludido relato incluya oraciones que, en último término, resultarán irrelevantes para los efectos de la calificación jurídica, y que, por tanto, es dudoso conferirles el estatus de hechos ${ }^{82}$. A la vez, el relato no siempre es suficientemente completo en la identificación de la conducta que se adscribe a una parte y que se hace calzar con la condición de aplicación de una norma. Para tales efectos, el intérprete suele buscar en distintas partes de la sentencia aquello que falta al fragmento del que no duda que contiene hechos probados.

La circunstancia de que los hechos sean decididos autoritativamente por los tribunales no los libera de que, ocasionalmente, padezcan de algunas patologías ${ }^{83}$. Entre

${ }^{80}$ Que los hechos sean constituidos no debiese resultar mayormente sorprendente, salvo que se suscriba a una corriente realista desde la perspectiva científica. Incluso para quienes defiendan formas de objetivismo, el entender que los hechos no son algo dado sino constituido, no representa un obstáculo. Vid. TORRETTI, 2010: 15-32 (esp. 15-17). Por cierto, el carácter de los hechos es especialmente fuerte en el mundo de los tribunales de justicia en los que se opera con reglas de exclusión de prueba y de limitación de los debates mucho más restrictivas que en otros contextos.

${ }^{81}$ Esta circunstancia incide en que no sea adecuado reconstruir los hechos como sucesos del pasado o fragmentos de la realidad. Parafraseando un texto de KELSEN en que aboga por el carácter constitutivo de los hechos (KELSEN, 1997: 249) puede sostenerse que no son los sucesos en sí sino los artefactos lingüísticos validados los que se acoplan con las normas. Aquello no resulta desafiado porque según nuestras formas usuales de hablar digamos, por ejemplo, que Ronnie fue encarcelado «porque asaltó un tren», en lugar de decir (más correctamente) «porque un tribunal competente, luego de seguir un procedimiento institucionalmente establecido, declaró que Ronnie asaltó un tren».

82 En ocasiones, las sentencias incorporan fragmentos discursivos escasamente comprometidos con aquello que resulta relevante desde la normativa aplicable. En casos así, pareciera que los tribunales: i) asumen una posición en la que se muestran interesados no solo en la solución del caso, sino en la reconstrucción de una experiencia de vida, o ii) no se ocupan de filtrar aquello que los testigos, peritos o abogados incorporan en el proceso, sin tener en consideración lo que desde la perspectiva procedimental resulta especialmente importante que aporten.

${ }^{83}$ Los sistemas actuales han resuelto otra importante patología — la suspensión de la toma de decisión factual— por la vía de consagrar el llamado principio de inexcusabilidad. 
ellas hay algunas que tienen un carácter eminentemente procedimental y otras que parecieran concernir directamente a los resultados alcanzados. La existencia de mecanismos correctivos de las patologías procedimentales ${ }^{84}$ no afecta el estatus de artefactos lingüísticos que cabe reconocer a los hechos. Se trata simplemente de que los requisitos para su validación no han sido cumplidos y, por ende, no es admisible relacionarlos con las normas que en términos generales y abstractos estipulan cargas y/o beneficios.

Las patologías concernientes a resultados para las que el sistema jurídico prevé remedios, son excepcionales. Los cambios a los cuales dan lugar (desde probado a no probado o viceversa) debilitan la idea de que la decisión acerca de los hechos es puramente constitutiva ${ }^{85}$. Las patologías de resultados suelen presentarse como de falsos positivos (se da por probado un hecho del cual hay buenas razones para sostener que no ocurrió) y de falsos negativos (se da por no probado un hecho del cual se carece de buenas razones para sostener que sí ocurrió). No es de extrañar, entonces, que la aparición de nuevos antecedentes incompatibles con la participación de uno o más sujetos a quienes se han adscrito conductas, o bien la deficiente motivación de una sentencia (escasamente sustentada en la prueba rendida) desafíen el estatus decisional de los hechos.

Aun cuando ocurra excepcionalmente, la privación de su estatus de definitividad que afecta a los hechos validados en una sentencia, constituye una razón para poner en duda la comprensión de los hechos como artefactos lingüísticos. Las sospechas — según es posible atisbar- apuntarían en el sentido de que si las razones invocadas no tienen que ver con problemas procedimentales sino con falsos positivos o con falsos negativos, los hechos no serían decididos, sino serían reconocidos. El asunto, sin embargo, no hace tambalear la conceptualización propuesta, aun cuando fuerza a realizar algunas precisiones adicionales.

El sistema jurídico cuando reconoce un medio de impugnación (recurso de revisión) respecto de aquello que se entendía que tenía el estatus de cosa juzgada, lo que hace es complejizar la secuencia de pasos requeridos para validar hechos. Así, es posible salir airoso de una objeción que aparece como del todo razonable y que refiere a que la definitividad de las decisiones supone ciertos límites en situaciones en las que perseverar en lo que ya ha sido dicho resultaría demasiado costoso, en términos de legitimidad. En rigor, para revisar las sentencias cuando ocurre algo inesperado - por ejemplo, aparece quien había sido declarado víctima de un homicidio - no prima tanto el reconocimiento de un falso positivo, sino la inconveniencia de perseverar en la consideración de un artefacto lingüístico que entra en abierta tensión con la prueba actualmente disponible.

${ }^{84}$ No se profundizará en las patologías procedimentales ya que no desafían la noción de artefacto lingüístico que es la que aquí interesa evaluar. Basta aclarar que ellas se producen, por ejemplo, cuando la decisión se funda en prueba inadmisible, no se respeta la forma institucionalizada de valorar la prueba, etc. Las modificaciones a las que dan lugar no se vinculan a qué se decidió, sino a cómo se decidió.

${ }^{85} \mathrm{Si}$ se le preguntase a tres árbitros acerca de cómo se determina la existencia de un gol, el primero podría indicar que él los cobra cuando un equipo los anota; el segundo, que los cobra cuando los ve; y el tercero, que no hay goles mientras él no los cobre (con esto parafraseo a POSNER, 2011: 98). Un sistema de recursos que ponga la atención en lo puramente procedimental, en principio, implicaría una concepción de los hechos cercana al tercer árbitro (no se cumplieron las condiciones para hacer el cobro), siendo compatible también con la del segundo árbitro (no consideró lo que debió haber visto). Los reparos focalizados en el resultado son más próximos a la perspectiva del primer árbitro (hubo un gol y no se cobró). 
Para entender mejor el problema precedente, vale la pena introducir un par de conceptos en tensión: me refiero a los de seguridad cognitiva y de responsabilidad cognitiva. El primero es útil para hacer frente al inmovilismo que va aparejado a un estado de duda permanente (la seguridad cognitiva aspira a la clausura de futuras problematizaciones respecto de un punto de vista aceptado). El segundo, en cambio, propende a la realización de la mayor cantidad de instancias de corroboración y de refutación posibles para la aceptación o rechazo de una conjetura. Cuando se trata de problemas teóricos, la responsabilidad cognitiva suele ocupar un lugar de privilegio: solo en aquello en que se ha sido altamente responsable, se debiera adoptar una actitud de seguridad en términos cognitivos. Cuando se trata de problemas prácticos, la seguridad cognitiva requerida fija los niveles de responsabilidad. El éxito de los hechos probados supone un adecuado equilibrio entre perspectivas en las que se hace predominar un estado de alta seguridad cognitiva a costa de una responsabilidad cognitiva comparativamente baja y aquellas, en que la responsabilidad cognitiva es alta, pero la seguridad cognitiva es reducida ${ }^{86}$. Un estado equilibrado de seguridad cognitiva implica gestionar la incertidumbre en términos de que no resulte inmovilizadora a los efectos de tomar una decisión. Un estado de equilibrio en lo que atañe a la responsabilidad cognitiva implica ejecutar esfuerzos suficientes para detectar errores salvables en la fase probatoria. Conforme a lo señalado, la seguridad cognitiva es requerida para los efectos de que las decisiones tomadas por los tribunales de justicia redunden en cargas y/o beneficios que permanezcan estables en el tiempo para los intervinientes en un proceso judicial. El límite es el de una responsabilidad cognitiva básica que implica revisar aquello que socialmente resulta insostenible, a la luz de los nuevos antecedentes de los cuales se dispone. En otras palabras, el artefacto lingüístico que representan los hechos admite ser puesto en entredicho en una nueva fase que el sistema, en la medida de lo posible, preferiría evitar. Así, las cosas los hechos nunca se desentienden de su dimensión procedimental.

\section{ETAPAS PROBATORIAS Y CONCEPTOS A CONSIDERAR EN CADA UNA DE ELLAS}

La decisión de los hechos probados supone la superación de exigencias previstas en una sucesión de etapas institucionalmente definidas. Un hito del proceso probatorio está representado por la fijación de una conjetura o hipótesis (hechos a probar). Esta resulta clave a los efectos de determinar la manera en que se llevará a cabo la rendición de pruebas y la discusión entre las partes ${ }^{87}$. El paso siguiente supone la realización de una serie de actividades que apuntan de lleno, ya sea a la demostración o bien, a la refutación de la conjetura. Aquello supone la participación no solo de jueces y abogados, sino de distintos sujetos que asumen la responsabilidad de proveer información útil en

\footnotetext{
86 PEPPER, 1942: 44-45. El rol de los estándares de prueba resulta muy claro en este orden de cosas.

${ }^{87}$ No se debe entender conjetura o hipótesis en el sentido de una corazonada, sino como una cierta forma de relacionar lo que ofrecen demostrar las partes y lo que requiere el tribunal para legitimar la imposición de una carga sobre la demandada o acusada. En ese sentido, la determinación de los hechos a probar es una forma de ordenar lo que cabe presentar como prueba y aquello que vale la pena argumentar. Vid. PEPPER, 1942: 71 y ss.
} 
el contexto del proceso. El estatus de hecho probado se alcanza solo al momento en que se pronuncia una decisión autoritativa que declara superado el estándar de prueba institucionalmente establecido.

Un modelo conceptual para decidir hechos probados debe distinguir, entonces, tres etapas o niveles sucesivos: etapa preparatoria, etapa de producción de pruebas y argumentos y etapa de decisión/justificación ${ }^{88}$. En la primera de ellas, se adoptan decisiones útiles para la estructuración de las etapas que le sucederán; ello en una forma equiparable a la determinación de las reglas de un juego (las preguntas claves son: ¿qué debe probarse?, ¿quién debe probar? y ¿con qué se probará?) ${ }^{89}$. En la segunda etapa las partes despliegan sus recursos probatorios y argumentativos cuidando de no excederse del marco de actuación fijado en la etapa preparatoria, como tampoco de lo estipulado en algunas reglas procedimentales del sistema (las preguntas claves son: ¿es válida la prueba que se presenta?, ¿la prueba rendida corrobora o refuta lo que se busca probar? $)^{90}$. En la fase de decisión y de justificación el protagonismo lo adquiere el tribunal quien zanja la disputa y provee de las razones para su elección (las preguntas claves son: ¿qué se ha probado?, ¿cuánto se ha probado?, ¿cómo se ha probado?) ${ }^{91}$.

La secuencia seguida para validar un hecho se representa en el cuadro que se inserta a continuación. En la primera columna se incluyen los insumos institucionalmente reconocidos para enfrentar la respectiva etapa. En la segunda columna se da cuenta de la actividad principal de los jueces en la respectiva etapa. En la tercera columna se informa de los productos que resultan de la etapa. Por último, en la última de las columnas se anuncian los conceptos claves en cada etapa y se expresa brevemente cuál es la utilidad que prestan.

Según la secuencia precedente se estaría en condiciones de decir, por ejemplo, que en un sistema jurídico «un hecho se considera (válidamente) probado si la conjetura que fija su contenido en conformidad a un análisis de pertinencia ${ }^{92}$ se ha sometido a contrastación, mediante la rendición de pruebas relevantes, previamente declaradas

88 David ScHum distingue una etapa de descubrimiento, que, a la vez, se subdivide en generación y eliminación de hipótesis, como también de estructuración de los argumentos. La etapa siguiente es la de rendición de la prueba ante el tribunal; para terminar con una de deliberación y elección. Pese a la relevancia de la primera etapa de SCHUM, la he reducido al mínimo para focalizarme en el papel de los jueces. Estos, al menos bajo una lógica adversarial, cumplen un rol de guardianes de lo que puede y de lo que no puede hacerse. SCHUM, 1986: 831 y ss. Vid. también FerRer, 2007: 41-49; AlCALÁ-ZAMORA, 1965: 29.

89 La determinación de quién probará y cuánto probará vienen definidas por el procedimiento utilizado (carga de la prueba y estándar de prueba).

90 Las tensiones tradicionales en el análisis de los modelos adversariales e inquisitivos que eran vistos como dos formas absolutamente diferenciadas de enfrentar los problemas de prueba, pareciere haberse matizado en el último tiempo. TARUFFO, 2006: 249-271. Vid. también DAMAŠKA, 2000: 12-32.

91 En un texto que próximamente será publicado («Conceptos y razonamientos probatorios») se diferencian para cada etapa clases de razonamiento preponderantes del tribunal y, en ocasiones, también de los abogados. Las categorías que pueden diferenciarse a tales efectos son tres: razonamiento dogmático (propone/ controla interpretaciones de disposiciones normativas); razonamiento epistémico (propone/controla inferencias y asigna valor a piezas de información), y razonamiento lógico (propone/controla la narración que da cuenta de lo que se da por probado o por no probado).

92 El concepto de pertinencia, tal como se usa en esta oración, apunta a la necesidad de delimitar lo que requiere ser probado en virtud de posibles relaciones entre los relatos ofrecido por las partes y las normas que pretenden ser aplicadas. Se hace cargo, entonces, de la relevancia de los hechos propuestos por las partes desde la perspectiva de su eventual acoplamiento con la condición de aplicación de una o más normas. Vid. VÁZQUEZ, 2015: 28 , nota 8 . 
admisibles, y de su valoración (lo que supone haber tomado en cuenta su credibilidad y fuerza probatoria), concluyéndose de todo ello que el estándar de prueba respectivo ha sido superado, y de lo cual se da cuenta en un texto que así lo justifica».

El modelo de decisión de los hechos cuyas bases aquí se proponen, presta utilidad a jueces y abogados respecto de las preguntas claves que cabe formular en los procesos judiciales, esto es ¿qué se prueba? (pertinencia); ¿quién prueba? (carga de la prueba); ¿con qué se prueba? (admisibilidad, relevancia, valoración); ¿cómo se prueba? (valoración de la prueba: credibilidad / fuerza probatoria, presunción) ¿cuánto se prueba? (estándar de prueba) y ¿cómo se hace constar lo que se prueba? (justificación). El desarrollo del modelo con mayor nivel de detalle será tratado en un texto posterior, ya que — según ha sido indicado— aquí solo se presentan sus bases.

\begin{tabular}{|c|c|c|c|}
\hline \multicolumn{4}{|c|}{ ETAPA DE PREPARACIÓN } \\
\hline Insumos & Actividad del juez & Productos & Conceptos asociados \\
\hline $\begin{array}{l}\text { - Relatos de las partes } \\
\text { (demanda/contesta- } \\
\text { ción). } \\
\text { - Normas sustantivas } \\
\text { que prima facie co- } \\
\text { rresponde aplicar. } \\
\text { - Pruebas obtenidas } \\
\text { en fase de investiga- } \\
\text { ción (algunos proce- } \\
\text { dimientos). }\end{array}$ & $\begin{array}{l}\rightarrow \text { Formular conje- } \\
\text { tura que se some- } \\
\text { terá a validación } \\
\text { en etapas siguien- } \\
\text { tes. } \\
\end{array}$ & $\begin{array}{l}\rightarrow \text { Artefacto provi- } \\
\text { sional: HECHOS } \\
\text { A PROBAR (con- } \\
\text { jetura). }\end{array}$ & $\begin{array}{l}\text { Pertinencia: orienta decisión so- } \\
\text { bre el tipo de conexiones que se } \\
\text { deben establecer entre los relatos } \\
\text { que ofrecen las partes y lo esti- } \\
\text { pulado en las normas que preten- } \\
\text { den aplicarse. } \\
\text { Carga de la prueba: anticipa cuál } \\
\text { de las partes será derrotada si no } \\
\text { presenta suficiente prueba en su } \\
\text { favor (relación estrecha con es- } \\
\text { tándar de prueba). }\end{array}$ \\
\hline $\begin{array}{l}\text { - Hechos a probar. } \\
\text { - Propuesta medios de } \\
\text { prueba. } \\
\text { - Reglas de admisibi- } \\
\text { lidad. }\end{array}$ & $\rightarrow \begin{array}{l}\text { Aceptar/rechazar } \\
\text { pruebas a rendir. }\end{array}$ & $\rightarrow \begin{array}{l}\text { MEDIOS } \\
\text { PRUEBA } \\
\text { tidos. }\end{array}$ & $\begin{array}{l}\text { Relevancia: orienta decisión sobre } \\
\text { valor probatorio mínimo exigible } \\
\text { a las fuentes de información que } \\
\text { ofrecen las partes, para ser admi- } \\
\text { tidas como medios de prueba. } \\
\text { Admisibilidad: indica propieda- } \\
\text { des que el sistema jurídico esti- } \\
\text { pula deben satisfacer los medios } \\
\text { de prueba que se presentarán. }\end{array}$ \\
\hline
\end{tabular}

\begin{tabular}{|c|c|c|c|}
\hline \multicolumn{4}{|c|}{ ETAPA DE PRODUCCIÓN DE PRUEBAS Y ARGUMENTOS } \\
\hline Insumos & Actividad del juez & Productos & Conceptos asociados \\
\hline $\begin{array}{l}\text { - Medios de prueba } \\
\text { que se presentan en } \\
\text { audiencia probatoria } \\
\text { y gestiones de aboga- } \\
\text { dos (interrogatorio, } \\
\text { contrainterrogatorio } \\
\text { de testigos, alega- } \\
\text { tos, etc.) } \\
\text { - Reglas de conduc- } \\
\text { ción de audiencias. }\end{array}$ & $\begin{array}{l}\rightarrow \text { Conducir audien- } \\
\text { cias. Aceptar/ } \\
\text { rechazar objecio- } \\
\text { nes. }\end{array}$ & $\begin{aligned} & \rightarrow \text { PRUEBA VÁ- } \\
& \text { LID A M ENTE } \\
& \text { RENDIDA (re- } \\
& \text { gistros). Propues- } \\
& \text { tas de VALORA- } \\
& \text { CIÓN DE LA } \\
& \text { PRUEBA (alega- } \\
& \text { tos de abogados). }\end{aligned}$ & $\begin{array}{l}\text { Valoración de la prueba: indica } \\
\text { formas válidas de construir in- } \\
\text { ferencias con la prueba rendida } \\
\text { (sana crítica, íntima convicción, } \\
\text { prueba tasada). } \\
\text { Credibilidad: orienta decisión } \\
\text { sobre valor que debe reconocer- } \\
\text { se a cada medio de prueba, de- } \\
\text { pendiendo de la fiabilidad de la } \\
\text { información. }\end{array}$ \\
\hline
\end{tabular}




\begin{tabular}{|c|c|c|c|}
\hline \multicolumn{4}{|c|}{ ETAPA DE DECISIÓN Y JUSTIFICACIÓN } \\
\hline Insumos & Actividad del juez & Productos & Conceptos asociados \\
\hline $\begin{array}{l}\text { - Prueba rendida. } \\
\text { - Alegatos de aboga- } \\
\text { dos. } \\
\text { - Reglas de valoración. } \\
\text { - Estándar de prueba. } \\
\text { - Reglas de motiva- } \\
\text { ción. }\end{array}$ & $\begin{array}{|lr|}\rightarrow \text { Aceptar/rechazar } \\
\text { adscripción r } & \text { de } \\
\text { conductas. } & \text { Re- } \\
\text { dactar texto justi- } \\
\text { ficativo. }\end{array}$ & $\begin{array}{l}\rightarrow \text { Artefactor lin- } \\
\text { gǘstico defini- } \\
\text { tivo (HECHOS } \\
\text { PROB A DOS / } \\
\text { NO PROBA- } \\
\text { DOS) JUSTIFI- } \\
\text { CACIÓN de de- } \\
\text { cisión probatoria } \\
\text { (sentencia). }\end{array}$ & $\begin{array}{l}\text { Valor probatorio (fuerza probato- } \\
\text { ria): orienta decisión sobre la in- } \\
\text { cidencia que debe reconocerse a } \\
\text { una o más pruebas rendidas para } \\
\text { demostrar/refutar la conjetura. } \\
\text { Estándar de prueba: orienta la de- } \\
\text { cisión de dar por probados o no } \\
\text { probados los hechos en el caso } \\
\text { concreto según suficiencia de la } \\
\text { prueba y diferenciando según el } \\
\text { tipo de procedimiento. }\end{array}$ \\
\hline
\end{tabular}

\section{CONCLUSIONES}

1. Los modelos conceptuales que se construyen en el ámbito jurídico, si bien no corresponden a aplicaciones tecnológicas estrictas de lo que teóricamente se encuentra validado, resultan útiles para que jueces y abogados enfrenten satisfactoriamente los distintos desafíos que se les presentan en el ejercicio de sus funciones.

2. A partir del concepto de «los hechos» es factible proponer un modelo conceptual para la gestión de problemas probatorios. Los hechos admiten diferenciarse en distintas categorías, siendo la de «hechos probados» la de mayor utilidad para los efectos de organizar el modelo.

3. Los hechos son un artefacto lingüístico que adscribe (1) acciones u omisiones jurídicamente relevantes sobre uno o más sujetos, (2) y que habiendo sido sometido a un proceso de comprobación/refutación (3) ha superado el estándar de prueba institucionalmente establecido.

4. La decisión o fijación de los hechos (probados) admite reconstruirse en tres niveles. En cada uno de ellos hay conceptos que depurar: $a$ ) el primer nivel es preparatorio. Corresponde a la construcción de una conjetura bajo la forma de un texto que atribuye conductas normativamente relevantes a uno o más sujetos, a lo que se suma la determinación de los medios de prueba a utilizar. En este nivel deben tenerse especialmente presentes los conceptos de pertinencia, relevancia, admisibilidad y carga de la prueba; $b$ ) el segundo nivel es de producción de pruebas y argumentos. Corresponde a la fase de contrastación de la conjetura con los medios de prueba y con las generalizaciones legal/culturalmente asentadas. En este nivel emergen algunos conceptos propios de la valoración de la prueba, como son los de fuerza probatoria y credibilidad, y c) el tercer nivel es de evaluación. Implica el paso institucional desde lo provisional hacia lo definitivo (los hechos), haciéndose cargo de lo que se ha generado en el proceso de demostración/refutación. En esta etapa son especialmente significativos los conceptos de estándar de prueba y de justificación (probatoria). 


\section{BIBLIOGRAFÍA CITADA}

AGÜERO, C., 2014: «¿Conforman las sentencias penales un género discursivo?», Estudios Filológicos, 53: 7-26.

Alcalá-Zamora, N., 1965: Estudios de Derecho Probatorio, Concepción: Universidad de Concepción.

Alchourrón, C., y Bulygin, E., 1991: «Los límites de la lógica y el razonamiento jurídico», en C. Alchourrón y E. Bulygin, Análisis lógico y derecho, Madrid: Centro de Estudios Constitucionales.

- 1993: Introducción a la metodología de las ciencias jurídicas y sociales (2. reimpresión), Buenos Aires: Astrea.

ALLEN, R., 2013: «Los estándares de prueba y los límites del análisis jurídicos», en C. VÁsQUEZ (ed.), Estándares de prueba y prueba científica, Madrid: Marcial Pons, 41-64.

Allen, R., y PARDO, M., 2003: «The Myth of the Law-Fact Distinction», Northwestern University Law Review, vol. 97, núm. 4.

Ambos, K., 2007: «100 años de la "teoría del delito" de Beling», Revista Electrónica de Ciencia Penal y Criminología. Disponible en bttp://criminet.ugr.es/recpc/09/recpc09-05.pdf (última visita: 29 de junio de 2016).

Anderson, T.; Schum, D., y Twining, W., 2015: Análisis de la prueba, Madrid: Marcial Pons.

ANDRÉs IBÁÑEZ, P., 1992: «Acerca de la motivación de los hechos en la sentencia penal», Doxa, 12: 257-299.

Bentham, J., 1971: Tratado de las pruebas judiciales, vol. 1, Buenos Aires: EJEA.

Berger, P., y Luckman, Th., 2006: La construcción social de la realidad (26. ${ }^{\text {a }}$ reimpresión), Buenos Aires-Madrid: Amorrortu.

CARr, N., 2015: Atrapados. Cómo las máquinas se apoderan de nuestras vidas, Bogotá: Taurus.

Celano, B., 1995: «Judicial decision and truth. Some remarks», en L. Gianformaggio y S. PAUlSON, Cognition and interpretation of law, Torino: G. Giappichelli.

Coloma, R., 2016a: «El Derecho Probatorio y su Torre de Babel. Sobre citas en revistas indexadas», Revista Derecho (Valdivia), 29 (2): 35-58.

— 2016b: «Las disciplinas jurídicas y su reinvención», Ius et Praxis, 22 (2): 253-298.

COlOMA, R., y AGÜERO, C., 2014: «Lógica, ciencia y experiencia en la valoración de la prueba», Revista Chilena de Derecho, 41 (2): 673-703.

Comanducci, P., 2009: Razonamiento Jurídico (2. ${ }^{a}$ reimpresión), México D. F.: Fontamara.

Couture, E., 2014: Fundamentos del Derecho Procesal Civil (5. ${ }^{a}$ reimpresión, 4. ${ }^{\text {a }}$ ed.), Montevideo: $\mathrm{B}$ de F.

DAmASKA, M., 2000: Las caras de la justicia y del poder del Estado, Santiago: Editorial Jurídica de Chile.

Di Robilant, E., 1968: Modelli nella filosofia del diritto, Bolonia: Il Mulino.

DuXbury, N., 1999: Random justice. On lotteries and legal decision-making, Oxford: Clarendon Press.

FERRER, J., 2005: Prueba y verdad en el derecho (2. ${ }^{\text {a }}$ ed.), Madrid: Marcial Pons.

- 2007: La valoración racional de la prueba, Madrid: Marcial Pons.

Fox, J., 1899: «Law and fact», Harvard Law Rev. (12).

GASCÓN, M., 1999: Los hechos en el Derecho. Bases argumentales de la prueba, Madrid: Marcial Pons. 
GONZÁLEZ, D., 2013: «Hechos y conceptos: sobre la relevancia de los conceptos para la prueba de los hechos», en D. GonZÁLEZ, Quaestio facti. Ensayos sobre prueba, causalidad y acción, México D. F.: Fontamara, 75-85.

HANSON, N., 1977: Patrones de descubrimiento. Investigación de las bases conceptuales de la ciencia, Madrid: Alianza.

Hart, H. L. A., 1995: El concepto de derecho, Buenos Aires: Abeledo-Perrot.

Ho, H. L., 2010: A Philosophy of Evidence Law (reimpresión), Oxford: Oxford University Press. Holmes, O. W., 2012: La senda del Derecho, Madrid: Marcial Pons.

JAKOBS, G., 2008: El derecho penal como disciplina científica (1. ${ }^{a}$ ed.), Navarra: Civitas.

Kahneman, D., 2012: Pensar rápido, pensar despacio (1. ed.), Buenos Aires: Debate.

KanT, I., 1973: Crítica de la razón pura (t. I, 7. ea ed.), Buenos Aires: Losada.

Kelsen, H., 1997: Teoría pura del derecho (9. ${ }^{a}$ ed., trad. R. Vernengo), México: Porrúa.

KoYré, A., 1994: «Del mundo del "aproximadamente” al universo de la precisión», en A. KoYRÉ, Pensar la ciencia, Barcelona: Paidós, 117-145.

LAUdAn, L., 2013: Verdad, error y proceso penal, Madrid: Marcial Pons.

— 2005: «Por qué un estándar de prueba subjetivo y ambiguo no es un estándar», Doxa, 28: 95-113.

MACCormick, N., 2007: «La argumentación silogística: una defensa matizada», Doxa, 30: 321 334.

Mosterín, J., 2008: Lo mejor posible. Racionalidad y acción bumana, Madrid: Alianza Editorial.

— 2013: «Modelos simples de un mundo complejo»», en J. MOSTERín, Ciencia, filosofía y racionalidad, Barcelona: Gedisa.

PARK, R., y SAKS, M., 2006: «Evidence Scholarship Reconsidered: Results of the Interdisciplinary Turn», Boston College Law Review (47): 949-1031.

PePper, S., 1942: World hypotheses (reimpresión), Berkeley: University of California Press.

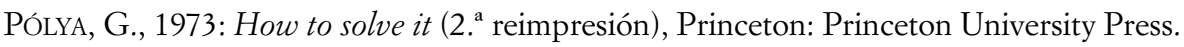

Posner, R., 2011: Cómo deciden los jueces, Madrid: Marcial Pons.

Schauer, F., 2013: Pensar como un abogado, Madrid: Marcial Pons.

Schum, D., 1986: «Probability and the Processes of Discovery, Proof, and Choice», Boston University Law Review (66).

TARufFo, M., 2006: «Poderes probatorios de las partes y del juez en Europa», Doxa (29): 249271.

- 2008: «¿Verdad negociada?», Revista de Derecho (Valdivia) (XXI), 1: 129-151.

TORRETTI, R., 2010: «La objetividad —en el sentido de Kant—», Estudios Filosóficos, 2007 2009, Santiago: Universidad Diego Portales, 15-32.

- 2012: Inventar para entender, Santiago: Universidad Diego Portales.

Twining, W., 1990: «The Rationalist Tradition of Evidence Scholarship», en W. TwINING, Rethinking Evidence, Evanston: Northwestern University Press.

- 1994: «Some scepticism about some scepticisms», en W. TwINING, Rethinking Evidence, Evanston: Northwestern University Press.

- 1997: «Pericles and the plumber», en W. Twining, Law in context, Oxford: Clarendon Press.

— 2007: «Argumentation, stories and generalizations: a comment», Law, Probability E Risk, vol. 6, Issue 1-4: 169-185.

VARGA, C., 1995: Theory of the judicial process. The establishment of facts, Budapest: Académiai Kiadó. 
VÁZQUeZ, C., 2015: De la prueba cientifica a la prueba pericial, Madrid: Marcial Pons.

Whitman, J., 2008: The origins of reasonable doubt. Theological roots of the criminal trial, New Haven \& London: Yale University Press.

WitTGENSTEIn, L., 2000: Sobre la certeza (2. reimpresión), Barcelona: Gedisa.

- 2004: Investigaciones Filosóficas (3. ${ }^{\mathrm{a}}$ ed.), Barcelona: Crítica.

WRÓBLEWSKI, J., 1974: «Legal syllogism and rationality of judicial decision», Rechtstheorie, 4: $33-46$.

- 1989: «Ideología de la aplicación judicial del Derecho», en J. WRóBLEWSKI, Sentido y hecho en el derecho, San Sebastián: Universidad del País Vasco, 67-84. 